\title{
Herding in China Equity Market
}

\author{
Tzewei Fu (corresponding author) \\ Department of Finance, National Defense University \\ Beitou District, Taipei ,Taiwan ( R.O.C.) \\ E-mail: futzewei@gmail.com
}

Monli Lin

Department of International Trade, Takming University of Science and Technology

Neihu District, Taipei, Taiwan (R.O.C.)

E-mail:monlilin@yahoo.com.tw

\begin{abstract}
This study explores herding behavior and investors' asymmetric reactions to good news and bad news in China equity market. Turnover effect on herding is tested. Data covers from Jan 2004 to June 2009, including current financial panic period.

Even though there do not exist herding behavior in China equity market, we demonstrate the existence of asymmetric reaction that investors' tendency toward herding is significantly higher during market downstream. This study partly supports the turnover effect that low turnover stocks significantly converge to market return than high turnover stocks during extreme market conditions.
\end{abstract}

Keywords: China equity market, Herd, Turnover rate, Asymmetric reaction

\section{Introduction and literature reviews}

Herding is an irrational behavior and low information cost strengthens herding. Banerjee (1992) defines herding as 'everyone doing what everyone else is doing, even when their information suggests doing something different'. Prechter and Parker (2007) suggest that uncertainty about valuation may cause herding. Kultti and Miettinen (2006) set up a standard sequential decision model; they purpose that if the cost of the information about the predecessors' actions is very expensive then all the agents will act according to their own signals. If observing is free one acts in herding behavior. Facing financial panic, investors may not have enough time to collect and analyze valuable information from many disorderly data. Investors may herd during financial panic.

Previous examinations of market wide herding have weak or no evidence and most of scholars use Cross-Sectional Standard Deviation (CSSD) or Cross-Sectional Absolute Deviation (CSAD) to measure the existence of herding. Christie and Huang (1995) find no herding using daily and monthly returns for NYSE and Amex firms; Chang, Chen and Khorana (2000) develop a non-linear model and find herding in South Korea and Taiwan markets, but do not find herding evidence in USA, Hong Kong and Japan markets. Gleason、 Mathur and Peterson (2004) find no herding behavior among the sector ETFS using intraday data of the American Stock Exchange. Caparrelli, D'Arcangelis and Cassuto (2004) examine Italian stock market and find a nonlinear relationship between the dispersion and returns. Henker, Henker and Mitsios (2006) find no market wide herding in Australian market.

Whether investors react asymmetric to good news and bad news is another topic. Christie and Huang (1995) do not support asymmetry, while Chang et al. (2000) show that herding measure is higher when market is declining than it is advancing. Henker et al. (2006) find partly support.

This study purposes that turnover rate (traded volume/total shares) may influence herding. No previous studies discuss the turnover rate, we purpose that low turnover rate stocks may have higher tendency to herd market. Gregroriou and Ioannidis (2006) use FTSE 100 data and find that high trading volume stocks have more available information. Chordia and Swaminathan (2000) find low trading volume stocks respond more slowly to information. Avery and Zemsky (1998) point out that as investors have no sufficient information; they may observe and follow other investors' action. Based on above empirical findings, we hypothesize the turnover effect on herding and will testify this effect in this study. Since there are no previous studies about turnover effect, the test of turnover effect is the most important contribution of this study.

Based on data of International Monetary Fund (2007), China equity market has 3.7 times growth during period 
2002 to 2006; world equity market grows only 1.87 times at the same period. Contrasting to the importance of China equity market in worldwide financial markets, there are scare researches discussing about herding behavior in China, one of the most prosperous emerging markets. Previous studies only discuss about the herding in dual-share. Zhou (2007) investigates the herding behavior in China's A and B markets and finds the existence of significant herding in both A and B share markets. Chong and Su (2006) examine the co-movement between the A shares and $\mathrm{H}$ shares of twenty-one cross-listed Chinese companies and find a small portion of sample have a co-movement. Contrasting to previous studies focusing on herding in dual share, this study aims to discuss about the market wide herding in China in Shanghai market and Shenzhen market.

The remainder of this paper is partitioned as follows:(1) the methodology and data that include herding measurement 、 hypotheses and the source of data; (2) results of the empirical tests; (3) conclusions.

\section{Methodology and Data}

\subsection{Herding Measurement}

Christie and Huang (1995) and Chang et al. (2000) propose that investors herd during periods of high market volatility. When herd exists, the returns of individual stock converge towards the returns on the aggregate market - market index. Thus, herding results in a smaller difference between the returns on the individual stock and the market index. We use two alternative measures of dispersion, CSSD and CSAD, to identify herding behavior.

The cross-sectional standard deviation (CSSD) method is proposed by Christie and Huang (1995) and be expressed as

$$
C S S D_{t}=\sqrt{\frac{\sum_{i=1}^{N_{t}}\left(R_{i, t}-R_{m, t}\right)^{2}}{N_{t}-1}}
$$

Chang et al. (2000) define the cross-sectional absolute deviation (CSAD) as

$$
C S A D_{t}=\frac{1}{N_{t}} \sum_{i=1}^{N_{t}}\left|R_{i, t}-R_{m, t}\right|
$$

In this study, $R_{i, t}$ is the return of stock $i$ during time period $t ; R_{m, t}$ is the return of market index during the same time period $t ; N_{t}$ is the number of stock listed in equity market during time period $t$. Shanghai equity market and Shenzhen equity market have their own CSSD and CSAD values at time period $t$. Shanghai composite index and Shenzhen composite index are used as proxies to measure Shanghai equity market index and Shenzhen equity market index.

\subsection{Test of Herding}

Herding will be more prevalent during periods of market stress, which is defined in terms of extreme market returns.

$$
C S S D_{t}=\alpha+\beta_{1} D_{t}^{U}+\beta_{2} D_{t}^{L}+\varepsilon_{t}
$$

Where

$D_{t}^{U}=1$, if the return on the market for time period $t$ lies in the extreme upper tail of the returns distribution, and

$D_{t}^{L}=1$, if the return on the market for time period $t$ lies in the extreme lower tail of the returns distribution,

This study adopts 5\% to define extreme market upward and downward. If herd exists, $\mathrm{CSSD}_{t}$ will be smaller during periods of market stress. Statistically significant negative values for $\beta_{1}$ and $\beta_{2}$ would indicate the presence of herding.

If individual is rational, individual asset should have different sensitivity to the market return. So, $\beta_{1}$ and $\beta_{2}$ be zero, or not significantly positive and negative, indicates that rational model is fit.

Chang et al. (2000) argue that the model in Eq. (3) requires defining what is meant by market stress and they propose a nonlinear relationship between CSAD and market return as follows:

$$
C S A D_{t}=\theta+\gamma_{1}\left|R_{m, t}\right|+\gamma_{2} R_{m, t}^{2}+\varepsilon_{t}
$$

If herd exists, then $\gamma_{2}$ will be significantly negative. 
Gleason et al. (2004) suggest dependent variables in Eqs. (3) and (4) could be swapped, which are expressed in the following equations:

$$
\begin{aligned}
& \operatorname{CSAD}_{t}=\alpha+\beta_{1} D_{t}^{U}+\beta_{2} D_{t}^{L}+\varepsilon_{t} \\
& \operatorname{CSSD}_{t}=\theta+\gamma_{1}\left|R_{m, t}\right|+\gamma_{2} R_{m, t}^{2}+\varepsilon_{t}
\end{aligned}
$$

To test the turnover rate (traded volume/ total shares) effect on herding, we define High Turnover Standard Deviation $(H T S D)$ 、 Low Turnover Standard Deviation (LTSD)、High Turnover Absolute Deviation $(H T A D)$ and Low Turnover Absolute Deviation (LTAD) as follows:

$$
\begin{gathered}
\text { HTSD }_{t}=\sqrt{\frac{\sum_{h=1}^{N_{t} / 2}\left(R_{h, t}-R_{m, t}\right)^{2}}{N_{t} / 2}} \\
\operatorname{LTSD}_{t}=\sqrt{\frac{\sum_{l=1}^{N_{t} / 2}\left(R_{l, t}-R_{m, t}\right)^{2}}{N_{t} / 2}} \\
\operatorname{HTAD}_{t}=\frac{1}{2 N_{t}} \sum_{h=1}^{N_{t} / 2}\left|R_{h, t}-R_{m, t}\right| \\
\operatorname{LTAD}_{t}=\frac{1}{2 N_{t}} \sum_{l=1}^{N_{t} / 2}\left|R_{l, t}-R_{m, t}\right|
\end{gathered}
$$

Where $t$ is time period, $\mathrm{R}_{i}$ is return of stocks $i . \mathrm{R}_{m, t}$ is market return. When a stock's turnover rate is higher than median value of turnover at the same time period (month) in the same stock market, this stock is classified into high turnover stock $\left(\mathrm{R}_{h, t}\right)$; otherwise, it is a low turnover $\operatorname{stock}\left(\mathrm{R}_{l, t}\right) . \mathrm{N} t$ is the number of stock at time period t. Shanghai market and Shenzhen market has its own four herding measures, HTSD、LTSD、HTAD and $L T A D$ for each month. To verify the turnover effect on herding, these four herding measures are treated as dependent variable in Eqs. (3) to (6).

\subsection{Herding Hypothesis}

We hypothesize low turnover stock will have higher tendency to herd market return. The HTSD and HTAD are used to measure the degree of high turnover rate stocks disperse from market return; the LTSD and LTAD are used to measure the degree of low turnover rate stocks disperse from market return. Based on the statements of Gregroriou and Ioannidis (2006) and Avery and Zemsky (1998), low turnover stock is lacking sufficient information and the lack of information will lead low turnover stock more tender to herd market return than high turnover stock. Low dispersion from market return means higher tendency to herd market. If turnover rate effect exists, the dispersion measurements, $\mathrm{SD}, \mathrm{AD}$, should be higher when turnover rate is high.

Hypothesis 1: The mean value of HTSD (HTAD) will be significantly higher than LTSD (LTAD).

Herding is information dissemination. During extreme market situation, noise traders do not know the value of new information and need to make decision in a short period; they will herd. Based on Kultti and Miettinen (2006), it takes no cost to observe the change of market return; investors will tend to herd market return during extreme market situation. Herding is an irrational behavior and does not follow traditional hypothesis that people are rational. Based on traditional market hypothesis such as the Capital Asset Pricing Model that investors are rational then herd will not exist. To test the existence of herding and turnover effect on herding, regression models, Equation 11 and Equation 12 are used. These two equations are similar to Equation 3 and Equation 4, but the dependent variable $\mathrm{Y}$ which is denoted as herding measures: CSSD, CSAD, HTSD, LTSD, HTAD and LTAD.

$$
\begin{gathered}
Y_{t}=\alpha+\beta_{1} D_{t}^{U}+\beta_{2} D_{t}^{L}+\varepsilon_{t} \\
Y_{t}=\theta+\gamma_{1}\left|R_{m, t}\right|+\gamma_{2} R_{m, t}^{2}+\varepsilon_{t}
\end{gathered}
$$

The percentage of upper or lower tail of market return distribution can be set up as we want, and present study 
uses $5 \%$.

Similar to the regression models of many researchers such as Christie and Huang (1995) and Chang et al. (2000), the coefficient of $\beta_{1}, \beta_{2}$ or $\gamma_{2}$ are used to test herd. If herd exists in China equity market during extreme market situation, the value of CSSD or CSAD will become smaller, this means that $\beta_{1}, \beta_{2}$ or $\gamma_{2}$ will be significantly negative. The significantly negative $\beta_{1}$ means investors herd during extreme upward market situation. The significantly negative $\beta_{2}$ means investors herd during extreme downward market situation. The significantly negative $\gamma_{2}$ means investors herd during extreme upward and downward market situation.

Hypothesis 2: If $\beta_{1}, \beta_{2}$ or $\gamma_{2}$ are significantly negative when dependent variables are CSSD and CSAD, herd exists in China equity market.

\subsection{Turnover Effect Hypothesis}

To testify the turnover effect, the sample is divided into two groups based on the turnover value of the stocks in each market, Shanghai and Shenzhen. The value of HTSD,LTSD,HTAD and LTAD will be calculated for each month. If turnover effect exists, the value of $L T S D$ or $L T A D$ will become significantly smaller during extreme market situations, while HTSD or HTAD will not become significantly smaller during extreme market. This means that $\beta_{1}, \beta_{2}$ or $\gamma_{2}$ are significantly negative only when dependent variables are LTSD or LTAD; and $\beta_{1,} \beta_{2}$ or $\gamma_{2}$ are not significantly negative when dependent variables are HTSD or HTAD.

Hypothesis 3: If turnover effect exists, $\beta_{1} \beta_{2}$ or $\gamma_{2}$ are significantly negative only when dependent variables are LTSD or LTAD.

\subsection{Asymmetric Reaction}

To ground on Christie and Huang (1995) and Chang et al. (2000), markets' reactions towards good news and bad news would appear to be diverse; If the dispersion is higher in up market, relative to down market, it is because investors are more fear of the extreme movements in down market.

Christie and Huang (1995) use the difference between $\beta_{1}$ and $\beta_{2}$ to measure asymmetric reaction. $\beta_{1}$ and $\beta_{2}$ are estimated based on Equation (11) and the dependent variable Y denotes as dispersion measures: CSSD, CSAD, HTSD, LTSD, HTAD and LTAD.

Chang et al. (2000) suggest other models to verify the asymmetric reaction. Equation 13 is used when the monthly market return, $R_{m, t}$, is greater and equal to zero; this is the upward market. Equation 14 is used when the monthly return, $R_{m, t}$, is less than zero; this is the downward market. The

$$
\begin{gathered}
Y_{t}=\alpha+\gamma_{1} \text {,up }\left|R_{m, t}\right|+\gamma_{2, u p}\left(R_{m, t}\right)^{2}+\varepsilon_{t} \\
Y_{t}=\alpha+\gamma_{1, \text { down }}\left|R_{m, t}\right|+\gamma_{2, \text { down }}\left(R_{m, t}\right)^{2}+\varepsilon_{t}
\end{gathered}
$$

Hypothesis 4: If $\mathrm{H}_{0}: \beta_{1}-\beta_{2}=0\left(\gamma_{2, u p}-\gamma_{2, \text { down }}=0\right)$ is rejected, then the degree of herding appears to be asymmetric during up market and down market.

\subsection{Data}

We obtain monthly data of listed stocks and market index from China database of Taiwan economic journal (TEJ) for period January, 2004 to June, 2009 which covering current financial panic. Shanghai composite index and Shenzhen composite index are chosen as proxies of markets because these two indices are the longest existing index in respective market.

\section{Results}

\subsection{Descriptive statistics}

Table 1 shows that mean value of Shenzhen market return, $1.77 \%$, is higher than Shanghai market return, $1.456 \%$. Shenzhen's higher market return accompanies with higher standard deviation value. During the 66 months' sampling periods, Shanghai has 40 months' market return greater than zero. As for Shenzhen, there is 41 months" market return greater than zero. The mean value and standard deviation value of Cross-Sectional Standard Deviation (CSSD)、HTSD and LTSD of Shenzhen market are all higher than Shanghai market. The mean value and standard deviation value of Cross-Sectional Absolute Deviation (CSAD)、HTAD and LTAD of Shenzhen market are closer to Shanghai market.

Table 1 also shows that mean value of absolute deviation $(A D)$ is higher than mean value of standard deviation $(S D)$ in both markets. Mean value of HTSD is higher than LTSD in both markets; mean value of HTAD is higher 
than $L T A D$ in both markets. The mean value of HTSD and LTSD for Shanghai stock market is 0.032 and 0.019 , respectively. The difference between mean value of HTSD and LTSD for Shanghai stock market is 0.013 and $\mathrm{t}$ value of paired mean test is 2.01 , which is significant at $5 \%$. The mean value of $H T A D$ and $L T A D$ for Shanghai stock market is 0.114 and 0.087 , respectively. The difference between mean value of HTAD and LTAD for Shanghai stock market is 0.027 and $t$ value of paired mean test is 3.34, which is significant at $1 \%$.

The mean value of HTSD and LTSD for Shenzhen stock market is 0.059 and 0.019 , respectively. The difference between mean value of HTSD and LTSD for Shenzhen stock market is 0.033 and t value of paired mean test is 2.05 , which is significant at $5 \%$. The mean value of HTSD and $L T S D$ for Shanghai stock market is 0.032 and 0.019 , respectively. The difference between mean value of HTAD and LTAD for Shenzhen stock market is 0.037 and $t$ value of paired mean test is 4.67 , which is significant at $1 \%$. The above significant mean difference between HTSD (HTAD) and LTSD (LTAD) means low turnover stock has significant low dispersion from market return. This support hypothesis 1 that low turnover stocks has a significant tendency to herd than high turnover stocks.

\subsection{Herding test using Shanghai data}

Model A in Table 2 show that there do not exist herding behavior in Shanghai equity market. Here, the $\beta_{1}$ and $\beta_{2}$ coefficients are not significantly negative when different dependent variables are used, indicating no convergence of the individual stocks returns to the Shanghai composite index return. Five of six regressions show significantly positive $\beta_{I}$ coefficient, Shanghai's stocks demonstrate higher dispersion during extreme upward market situation.

Model B in Table 2 show the same results, there do not exist herding behavior in Shanghai equity market. The $\gamma_{2}$ is not significantly negative. This result points to the absence of herding during periods of high market stress in Shanghai.

The negative adjusted $\mathrm{R}$ square value is shown in Table 2 when Model B is implemented for HTSD. Based on the statement of Greene(1993), this is because X (independent variables)and Y (dependent variable) has a sample correlation of zero, but too many $\mathrm{X}$ are added into the regression model which will makes negative adjusted $\mathrm{R}$ square value.

\subsection{Herding test using Shenzhen data}

Model A in Table 3 show that there do not exist herding behavior in Shenzhen equity market. Here, the $\beta_{1}$ and $\beta_{2}$ coefficients are not significantly negative when different dependent variables are used, indicating no convergence of the individual stocks returns from the Shenzhen composite index return. One of the six regressions shows significantly positive $\beta_{l}$ coefficient, low turnover stocks demonstrate higher dispersion during extreme upward market situation.

Model B in Table 3 show the same results, there do not exist herding behavior in Shenzhen equity market. The $\gamma_{2}$ is not significantly negative. This result points to the absence of herding during periods of high market stress in Shenzhen.

Again, there are several negative adjusted $\mathrm{R}$ square values are shown in Table 3 . The explanation is that $\mathrm{X}$ (independent variables) and $\mathrm{Y}$ (dependent variable) has a sample correlation of zero, but too many $\mathrm{X}$ are added into the regression model.

The findings in 3.2 and 3.3 show that hypothesis 2 is not supported; there does not exist herding behavior in China equity market.

\subsection{Turnover effect on herding}

To evaluate the turnover effect on herding, we test hypothesis 3 to examine $\beta_{1}, \beta_{2}$ or $\gamma_{2}$ are significantly negative only when dependent variables are $L T S D$ or $L T A D$.

The results partly support turnover effect on herding. From Table 2 and Table 3, we can notice that regressions with different dependent variables coincidently show that $\beta_{1}, \beta_{2}$ or $\gamma_{2}$ are not significantly negative. Turnover effect does not exist in full samples.

We further analyze Table 4 and Table 5 which samples are divided into upward (market return is positive) sample and downward (market return is negative) sample. For Shanghai market, there is forty monthly market returns greater than zero, the upward market situations. The largest market return value is $27.4 \%$ and the lowest market return value is $0.19 \%$ in the upward market situation. As for the Shanghai downward market situation, market returns range from $-0.06 \%$ to $-23.6 \%$. For Shenzhen market, there is forty-one monthly market returns greater than zero, the upward market situations. During the upward market situation, market return ranges from $0.36 \%$ 
to $28.9 \%$. As for the Shenzhen downward market situation, market returns range from $-0.58 \%$ to $-23.4 \%$.

The coefficient of $\gamma_{2}$, down , -3.47 , is significantly negative when LTAD is dependent variable in evaluating Shenzhen equity market. Low turnover stocks show a significant tendency to herd market return during extreme downward situation in Shenzhen.

\subsection{Asymmetric reactions test}

All data support hypothesis 4, Investors have asymmetric reactions to good news and bad news. Shanghai investors' asymmetric reactions are shown in Table 4 . All regressions show that difference between $\beta 1$ and $\beta 2$ is significantly positive based on the $t$ value. Since the values of dependent variables are small, the coefficient value and the differences are also small but still significantly different. Herding is more likely to happen during downward market. Finding is consistent when based on Change et al. (2000), the difference between $\gamma_{2}$, up $-\gamma_{2}$, down is significantly positive. Result supports Shanghai investors tender to herd when facing bad news.

Shenzhen investors' asymmetric reactions are shown in Table 5. All regressions show that difference between $\beta 1$ and $\beta 2$ is significantly positive. Herding is more likely to happen during downward market. Finding is consistent when based on Change et al. (2000), the difference between $\gamma_{2}, u p-\gamma_{2}$,down is significantly positive. Result supports Shenzhen investors tender to herd when facing bad news.

\section{Conclusions}

We have six herding measures to examine investment behavior in China equity market. Even though this study does not support the existence of herding, we still have some interesting findings. Finding supports that low turnover stocks tend to herd than high turnover stock and investors tend to herd in downward market. The turnover effect on herding is partly supported; low turnover stocks show a significant tendency to herd market during extreme downward situation.

The finding can offer China government some suggestions in set up information mechanisms. Owing to investors tend to herd during downward market and low turnover stocks have significantly tendency toward herd than high turnover stocks, China government should establish an information monitoring system to regulate listed companies to offer prompt and sufficient information for investors to reduce herd in downward market and more rigid requirements should be set up for low turnover stocks.

\section{References}

Avery, C. and P. Zemsky. (1998). Multidimensional uncertainty and herd behavior in financial markets. American Economic Review, 88, 724-748.

Banerjee, A. (1992). A simple model of herd behavior. Quarterly Journal of Economics, 107(3), 797-818.

Caparrelli, F., A. M. D'Arcangelis and A. Cassuto.(2004). Herding in the Italian stock market: A Case of Behavior Finance.Journal of Behavioral Finance, 5(4), 222-230.

Chang, E., Cheng, J. and A. Khorana. (2000). An examination of herd behavior in equity markets: an international perspective. Journal of Banking and Finance, 24(10), 1651-1679.

Chong, T. L.and Q. Su. (2006). On the comovement of A and H shares. The Chinese Economy, 39(5), 68-86.

Chordia, T. and B. Swaminathan. (2000). Trading volume and cross-autocorrelations in stock returns. Journal of Finance, 55, 913-936.

Christie, W. and R. D. Huang. (1995). Following pied piper: do individual returns herd around the market?. Financial Analysts Journal, 51(4), 31-37.

Gleason, K., Mathur, I. and M. Peterson. (2004). Analysis of intraday herding behavior among the sector ETFs'. Journal of Empirical Finance, 11, 681-694.

Greene, W.H. (1993). Econometric Analysis, $2^{\text {nd }}$ edtion, Prentice-Hall Inc., New Jessey.

Gregroriou, A. and C. Ioannidis. (2006). Information costs and liquidity effects from changes in the FTSE 100 lits. The European Journal of Finance, 12(4), 347-360.

Henker, J., Henker, T .and A. Mitsios. (2006). Do investors herd intraday in Australian equities?. International Journal of Managerial Finance, 2(3), 196-219.

International Monetary Fund. (2007). Global Financial Stability Report, October 2007. http://www.imf.org/External/Pu/FT/GFSR/2007/.

Kultti, K. and P. Miettinen. (2006). Herding with costly information. International Game Theory Review, 8(1), 
21-31.

Prechter, R. and W. Parker. (2007). The financial/economic dichotomy in social behavioral dynamics: socionomic perspective. Journal of Behavioral Finance, 8(2), 84-108.

Zhou, H. (2007). Herding in dual-share stock markets: evidence from China. Journal of Emerging Markets, $12(2), 5-15$.

Table 1. Statistics data

\begin{tabular}{|c|c|c|c|c|c|c|c|c|c|}
\hline \multicolumn{5}{|c|}{ Shanghai equity market } & \multicolumn{5}{|c|}{ Shenzhen equity market } \\
\hline item & Mean & $\begin{array}{l}\text { Standard } \\
\text { deviation }\end{array}$ & $\begin{array}{l}\text { Maxi } \\
\text {-mum }\end{array}$ & $\begin{array}{l}\text { Mini } \\
\text {-mum }\end{array}$ & item & Mean & $\begin{array}{l}\text { Standard } \\
\text { deviation }\end{array}$ & $\begin{array}{l}\text { Maxi } \\
\text {-mum }\end{array}$ & $\begin{array}{l}\text { Mini } \\
\text {-mum }\end{array}$ \\
\hline $\begin{array}{l}\text { Composite } \\
\text { index } \\
\text { return }(\%)\end{array}$ & 1.456 & 9.8 & 27.5 & -23.6 & $\begin{array}{l}\text { Composite } \\
\text { index } \\
\text { return (\%) }\end{array}$ & 1.77 & 10.6 & 28.9 & -23.5 \\
\hline CSSD & 0.026 & 0.031 & 0.179 & 0.004 & $C S S D$ & 0.042 & 0.073 & 0.473 & 0.0004 \\
\hline HTSD & 0.032 & 0.041 & 0.312 & 0.006 & $H T S D$ & 0.059 & 0.107 & 0.745 & 0.007 \\
\hline$L T S D$ & 0.019 & 0.031 & 0.212 & 0.005 & $L T S D$ & 0.026 & 0.07 & 0.514 & 0.001 \\
\hline$C S A D$ & 0.101 & 0.046 & 0.233 & 0.046 & $C S A D$ & 0.099 & 0.041 & 0.240 & 0.046 \\
\hline HTAD & 0.114 & 0.045 & 0.238 & 0.058 & HTAD & 0.117 & 0.048 & 0.328 & 0.057 \\
\hline LTAD & 0.087 & 0.048 & 0.236 & 0.029 & LTAD & 0.080 & 0.045 & 0.247 & 0.031 \\
\hline
\end{tabular}

Table 2. Herding and Turnover effect in Shanghai equity market

\begin{tabular}{|c|c|c|c|c|c|c|}
\hline \multicolumn{7}{|c|}{ Model A: Dispersion $_{t}^{a}=\alpha+\beta_{1} D_{t}^{U}+\beta_{2} D_{t}^{L}+\varepsilon_{t}$} \\
\hline \multicolumn{7}{|c|}{ Model B: Dispersion $_{t}=\alpha+\gamma_{1}\left|R_{m, t}\right|+\gamma_{2} R_{m, t}{ }^{2}+\varepsilon_{t}$} \\
\hline Dispersion & $\beta_{1}$ & $\beta_{2}$ & $\operatorname{Adj} R^{2}$ & $\gamma_{1}$ & $\gamma_{2}$ & Adj $R^{2}$ \\
\hline$C S S D$ & $\begin{array}{c}0.065 \\
(3.92 * * *)\end{array}$ & $\begin{array}{l}-0.012 \\
(-0.71) \\
\end{array}$ & 0.179 & $\begin{array}{c}0.048 \\
(0.247) \\
\end{array}$ & $\begin{array}{c}0.348 \\
(0.428) \\
\end{array}$ & 0.037 \\
\hline HTSD & $\begin{array}{l}0.047 \\
(1.95) \\
\end{array}$ & $\begin{array}{l}-0.016 \\
(-0.66) \\
\end{array}$ & 0.037 & $\begin{array}{c}0.151 \\
(0.570) \\
\end{array}$ & $\begin{array}{c}-0.255 \\
(-0.229) \\
\end{array}$ & -0.011 \\
\hline LTSD & $\begin{array}{c}0.082 \\
\left(5.41^{* * *}\right)\end{array}$ & $\begin{array}{l}-0.008 \\
(-0.51)\end{array}$ & 0.300 & $\begin{array}{c}-0.057 \\
(-0.304) \\
\end{array}$ & $\begin{array}{l}0.956 \\
(1.22)\end{array}$ & 0.094 \\
\hline$C S A D$ & $\begin{array}{c}0.092 \\
(3.68 * * *)\end{array}$ & $\begin{array}{l}-0.014 \\
(-0.57)\end{array}$ & 0.157 & $\begin{array}{c}0.024 \\
(0.086)\end{array}$ & $\begin{array}{c}1.113 \\
(0.960)\end{array}$ & 0.120 \\
\hline HTAD & $\begin{array}{c}0.086 \\
(3.43 * * *)\end{array}$ & $\begin{array}{l}-0.017 \\
(-0.69) \\
\end{array}$ & 0.139 & $\begin{array}{c}0.009 \\
(0.033) \\
\end{array}$ & $\begin{array}{c}1.029 \\
(0.884) \\
\end{array}$ & 0.090 \\
\hline LTAD & $\begin{array}{c}0.089 \\
\left(3.31^{* * *}\right)\end{array}$ & $\begin{array}{c}-0.011 \\
(-0.417)\end{array}$ & 0.125 & $\begin{array}{c}0.037 \\
(0.129)\end{array}$ & $\begin{array}{c}1.128 \\
(0.932)\end{array}$ & 0.124 \\
\hline
\end{tabular}

Note: a. $D_{t}^{U}=1$, if the return on the market for time period $t$ lies in the extreme upper $5 \%$ of the returns distribution, and $D_{t}^{L}=1$, if the return on the market for time period $t$ lies in the extreme lower $5 \%$ of the returns distribution. Dispersion has several different measurements such as CSSD, CSAD, HTSD, LTSD, HTAD and LTAD.

$1 . * * *$ Significance at $1 \%$ level.

2. Value in parentheses is $t$ value. 
Table 3 Herding and turnover effect in Shenzhen equity market

\begin{tabular}{|c|c|c|c|c|c|c|}
\hline \multicolumn{7}{|c|}{ Model A: Dispersion $_{t}^{a}=\alpha+\beta_{1} D_{t}^{U}+\beta_{2} D_{t}^{L}+\varepsilon_{t}$} \\
\hline \multicolumn{7}{|c|}{ Model B: Dispersion $_{t}=\alpha+\gamma_{1}\left|R_{m, t}\right|+\gamma_{2} R_{m, t}{ }^{2}+\varepsilon_{t}$} \\
\hline Dispersion & & & & & & \\
\hline & $\beta_{1}$ & $\beta_{2}$ & Adj $R^{2}$ & $\gamma_{1}$ & $\gamma_{2}$ & Adj $R^{2}$ \\
\hline$C S S D$ & $\begin{array}{c}0.021 \\
(0.484)\end{array}$ & $\begin{array}{l}-0.027 \\
(-0.63)\end{array}$ & -0.021 & $\begin{array}{c}0.328 \\
(0.727) \\
\end{array}$ & $\begin{array}{c}-0.76 \\
(-0.43)\end{array}$ & -0.012 \\
\hline$H T S D$ & $\begin{array}{l}0.0014 \\
(0.022)\end{array}$ & $\begin{array}{l}-0.037 \\
(-0.58)\end{array}$ & -0.026 & $\begin{array}{c}0.220 \\
(0.328) \\
\end{array}$ & $\begin{array}{l}-0.634 \\
(-0.24)\end{array}$ & -0.029 \\
\hline LTSD & $\begin{array}{c}0.040 \\
(0.953) \\
\end{array}$ & $\begin{array}{l}-0.019 \\
(-0.45) \\
\end{array}$ & -0.013 & $\begin{array}{l}0.477 \\
(1.12) \\
\end{array}$ & $\begin{array}{c}-1.04 \\
(-0.620) \\
\end{array}$ & 0.018 \\
\hline$C S A D$ & $\begin{array}{l}0.049 \\
(2.08)\end{array}$ & $\begin{array}{c}-0.013 \\
(-0.563)\end{array}$ & 0.041 & $\begin{array}{c}0.197 \\
(0.807)\end{array}$ & $\begin{array}{l}-0.055 \\
(-0.057)\end{array}$ & 0.053 \\
\hline HTAD & $\begin{array}{c}0.022 \\
(0.774)\end{array}$ & $\begin{array}{l}-0.012 \\
(-0.41)\end{array}$ & -0.019 & $\begin{array}{c}0.404 \\
(1.39)\end{array}$ & $\begin{array}{c}-1.15 \\
(-1.00) \\
\end{array}$ & 0.014 \\
\hline LTAD & $\begin{array}{c}0.078 \\
(3.14 * * *)\end{array}$ & $\begin{array}{l}-0.012 \\
(-0.47)\end{array}$ & 0.113 & $\begin{array}{l}0.223 \\
(0.87)\end{array}$ & $\begin{array}{c}0.279 \\
(0.275)\end{array}$ & 0.143 \\
\hline
\end{tabular}

Note: a. $D_{t}^{U}=1$, if the return on the market for time period $t$ lies in the extreme upper $5 \%$ of the returns distribution, and $D_{t}^{L}=1$, if the return on the market for time period $t$ lies in the extreme lower $5 \%$ of the returns distribution. Dispersion has several different measurements such as CSSD, CSAD, HTSD, LTSD, HTAD and LTAD.

$1 . * * *$ Significance at $1 \%$ level.

2. Value in parentheses is $t$ value.

Table 4. Asymmetric test and turnover effect in Shanghai equity market

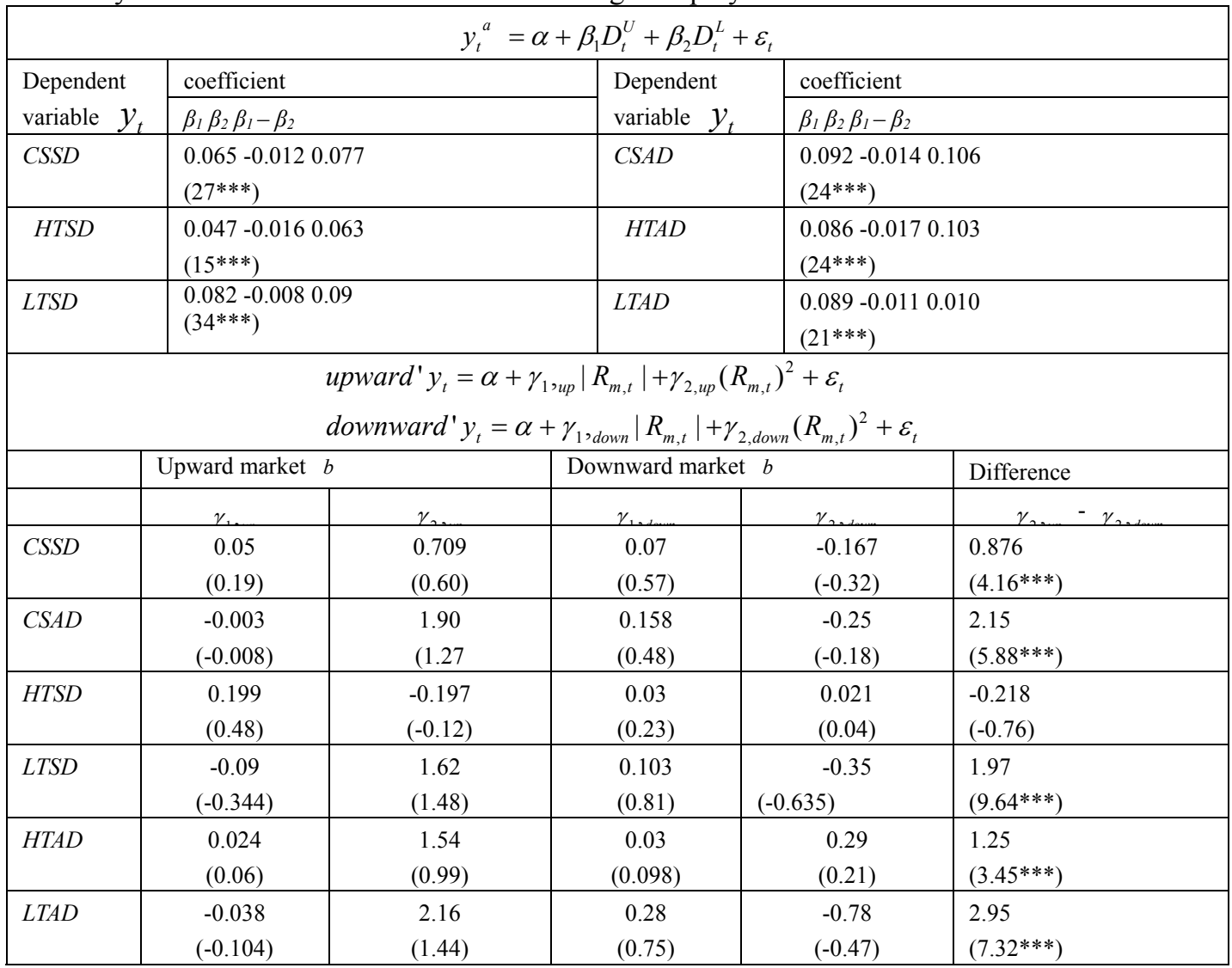

Note: a. $D_{t}^{U}=1$, if the return on the market for time period $t$ lies in the extreme upper $5 \%$ of the returns distribution, and $D_{t}^{L}=1$, if the return on 
the market for time period $t$ lies in the extreme lower $5 \%$ of the returns distribution. $y_{t}$ have several different measurements such as CSSD, CSAD, HTSD, LTSD, HTAD and LTAD.

b. upward market means monthly market return, $R_{m t}$, is greater and equal to zero; downward market means monthly return, $R_{m t}$, is less than zero.

1. *** Significance at $1 \%$ level.

2. Value in parentheses is $t$ value.

Table 5. Asymmetric test and turnover effect in Shenzhen equity market

\begin{tabular}{|c|c|c|c|c|c|}
\hline & \multicolumn{5}{|c|}{$y_{t}=\alpha+\beta_{1} D_{t}^{U}+\beta_{2} D_{t}^{L}+\varepsilon_{t}$} \\
\hline \multirow[t]{2}{*}{ Model } & \multicolumn{2}{|l|}{ coefficient } & Model & \multicolumn{2}{|l|}{ coefficient } \\
\hline & \multicolumn{2}{|l|}{$B_{1} \beta \beta_{1}-\beta_{2}$} & & \multicolumn{2}{|l|}{$\beta_{1} \beta_{2} \beta_{1}-\beta_{2}$} \\
\hline CSSD & \multicolumn{2}{|c|}{$0.021-0.0270 .048(6.39 * * *)$} & $C S A D$ & \multicolumn{2}{|c|}{$\begin{array}{l}0.049-0.0130 .062 \\
(15.2 * * *)\end{array}$} \\
\hline$H T S D$ & \multicolumn{2}{|c|}{$\begin{array}{l}0.001-0.0370 .038 \\
\left(3.44^{* * *}\right)\end{array}$} & $H T A D$ & \multicolumn{2}{|c|}{$\begin{array}{l}0.022-0.0120 .034 \\
(6.81 * * *)\end{array}$} \\
\hline LTSD & \multicolumn{2}{|c|}{$\begin{array}{l}0.040-0.0190 .059 \\
(8.04 * * *)\end{array}$} & LTAD & \multicolumn{2}{|c|}{$\begin{array}{l}0.078-0.0120 .090 \\
\left(20.8^{* * *}\right)\end{array}$} \\
\hline \multicolumn{6}{|c|}{$\begin{array}{l}\text { upward' } y_{t}=\theta+\gamma_{1, \text { up }}\left|R_{m, t}\right|+\gamma_{2, u p}\left(R_{m, t}\right)^{2}+\varepsilon_{t} \\
\text { downward' } y_{t}=\theta+\gamma_{1} \text {, down } \\
\left|R_{m, t}\right|+\gamma_{2, \text { down }}\left(R_{m, t}\right)^{2}+\varepsilon_{t}\end{array}$} \\
\hline & \multicolumn{2}{|c|}{ Upward market } & \multicolumn{2}{|c|}{ Downward market } & Difference \\
\hline & $\gamma_{.}$. & $\gamma_{2, \text { wn }}$ & $\gamma_{1}$,down & $\gamma_{2, \text { down }}$ & $-\gamma_{2}$, down \\
\hline$C S S D$ & $\begin{array}{l}0.282 \\
(0.43)\end{array}$ & $\begin{array}{c}-0.13 \\
(-0.39)\end{array}$ & $\begin{array}{l}0.513 \\
(1.49) \\
\end{array}$ & $\begin{array}{c}-1.75 \\
(-1.28) \\
\end{array}$ & $\begin{array}{c}1.42 \\
(2.94 * * *)\end{array}$ \\
\hline$C S A D$ & $\begin{array}{l}0.146 \\
(0.48)\end{array}$ & $\begin{array}{c}0.552 \\
(0.455)\end{array}$ & $\begin{array}{l}0.412 \\
(1.16)\end{array}$ & $\begin{array}{l}-1.41 \\
(-1.00)\end{array}$ & $\begin{array}{c}1.96 \\
(5.80 * * *)\end{array}$ \\
\hline$H T S D$ & $\begin{array}{c}-0.02 \\
(-0.02) \\
\end{array}$ & $\begin{array}{c}0.12 \\
(0.03)\end{array}$ & $\begin{array}{l}0.865 \\
(1.92)\end{array}$ & $\begin{array}{c}-2.77 \\
(-1.56) \\
\end{array}$ & $\begin{array}{c}2.88 \\
(4.10 * * *) \\
\end{array}$ \\
\hline LTSD & $\begin{array}{l}0.585 \\
(0.97) \\
\end{array}$ & $\begin{array}{c}-0.77 \\
(-0.32) \\
\end{array}$ & $\begin{array}{l}0.307 \\
(0.89) \\
\end{array}$ & $\begin{array}{c}-1.29 \\
(-0.94) \\
\end{array}$ & $\begin{array}{c}0.52 \\
(1.12) \\
\end{array}$ \\
\hline HTAD & $\begin{array}{l}0.308 \\
(0.79) \\
\end{array}$ & $\begin{array}{c}-0.72 \\
(-0.47) \\
\end{array}$ & $\begin{array}{l}0.687 \\
(1.79) \\
\end{array}$ & $\begin{array}{l}-2.27 \\
(-1.5) \\
\end{array}$ & $\left(4.00^{* * *}\right)^{1.55}$ \\
\hline LTAD & $\begin{array}{l}-0.015 \\
(-0.06)\end{array}$ & $\begin{array}{c}1.82 \\
(1.74)\end{array}$ & $\begin{array}{c}0.982 \\
(2.24 * *)\end{array}$ & $\begin{array}{c}-3.47 \\
(-2.00 * *)\end{array}$ & $\begin{array}{c}5.29 \\
\left(13.8^{* * *}\right)\end{array}$ \\
\hline
\end{tabular}

Note: a. $D_{t}^{U}=1$, if the return on the market for time period $t$ lies in the extreme upper $5 \%$ of the returns distribution, and $D_{t}^{L}=1$, if the return on the market for time period $t$ lies in the extreme lower $5 \%$ of the returns distribution. $y_{t}$ have several different measurements such as CSSD, CSAD, HTSD, LTSD, HTAD and LTAD.

b. upward market means monthly market return, $R_{m+}$, is greater and equal to zero; downward market means monthly return, $R_{m+}$, is less than zero.

1. *** Significance at $1 \%$ level.

2. Value in parentheses is t value. 